\title{
Mechanisms of the Electrodimerization of Activated Olefins. VIII. Negative Activation Enthalpies in the Dimerization of Diethyl Fumarate Anion Radical
}

\author{
MORTEN SVAAN and VERNON D. PARKER
}

Laboratory for Organic Chemistry, Norwegian Institute of Technology, University of Trondheim, N-7034 Trondheim-NTH, Norway

Electrode kinetic studies were carried out on the electrohydrodimerization of diethyl fumarate in acetonitrile containing water. The reaction was observed to be second order in anion radical and approximately first order in water. Over a wide range of water concentration the enthalpy of activation was observed to be of the order of $-4 / \mathrm{kcal} / \mathrm{mol}$ with an entropy of activation close to $-50 \mathrm{cal} / \mathrm{K} \mathrm{mol}$. The mechanism of the reaction consists of hydrogen bonding equilibrium (i) followed by rate determining coupling reaction (ii).

(i) $\left(\mathrm{EtO}_{2} \mathrm{C}-\mathrm{CH}=\mathrm{CH}-\mathrm{CO}_{2} \mathrm{Et}\right)^{\cdot-}+\mathrm{HOH} / \mathrm{CH}_{3} \mathrm{CN} \stackrel{\mathrm{K}_{\mathrm{i}}}{\rightleftarrows} \mathrm{DEF} \cdot-/ \mathrm{H}_{2} \mathrm{O}+\mathrm{CH}_{3} \mathrm{CN}$

(ii) $\mathrm{DEF}^{\cdot-} / \mathrm{H}_{2} \mathbf{O}+\mathrm{DEF}^{\cdot-} \stackrel{k_{\text {ii }}}{\longrightarrow}$ dimer

The mechanism is discussed in relation to other cases in reactive intermediate chemistry where negative activation enthalpies are observed.

The previous paper ${ }^{7}$ in this series ${ }^{1-7}$ dealt with the examination of rate-activation energy relationships for the dimerization reactions of ion radicals. Experimental results were presented for the dimerization of diethyl fumarate (DEF) anion radical in $N, N$ dimethylformamide (DMF) containing water and sometimes alkali metal cations. The reactions were found to follow general mechanism (1)-(2) in which $\mathrm{X}$ was either

$$
\begin{aligned}
& \mathrm{A}^{\cdot-}+\mathrm{X} \stackrel{K_{1}}{\longrightarrow} \mathrm{A}^{\cdot-} / \mathrm{X} \\
& \mathrm{A}^{\cdot-} / \mathrm{X}+\mathrm{A}^{\cdot-} \stackrel{k_{2}}{\longrightarrow} \text { Dimer }
\end{aligned}
$$

water, hydrogen bonded to the solvent, or alkali metal cation and $\mathrm{A}^{\cdot-}$ is the anion radical of the substrate. Simple dimerization of the anion radical (3) was not observed and it was proposed that

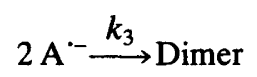


about $10 \mathrm{M}^{-1} \mathrm{~s}^{-1}$ is the maximum value of $k_{3}$ at ambient temperature. When $\mathrm{X}$ was water, $\Delta H^{+}$was observed to be $1.3 \mathrm{kcal} / \mathrm{mol}$. It was also possible to determine $\Delta H_{1}^{\circ}$ for reaction (1) to be equal to $-5.9 \mathrm{kcal} / \mathrm{mol}$. Thus $\Delta H_{2}^{*}$ is of the order of $7.2 \mathrm{kcal} / \mathrm{mol}$ and $\Delta H_{3}^{*}$ was estimated to be of the order of $11 \mathrm{kcal} / \mathrm{mol}$ or greater. The general conclusion of the study was that the activation parameters of ion radical reactions are not unusual in comparison to those for other reactive intermediate reactions and are a valuable guide in assigning mechanisms for complex reactions. The use of such arguments had previously been questioned and it had incorrectly been suggested that the procedure neglects results from classical chemical kinetics. ${ }^{8}$

The very low $\Delta H^{*}$ observed for the dimerization of $\mathrm{DEF}^{--}$in DMF, i.e. $1.3 \mathrm{kcal} / \mathrm{mol}$, is clearly out of the range expected for a reaction with a second order rate constant at room temperature of the order of $400 \mathrm{M}^{-1} \mathrm{~s}^{-1}$ (at a water concentration of $0.5 \mathrm{M}$ ). Diffusion controlled reactions are expected to have activation energies of the order of $3 \mathrm{kcal} / \mathrm{mol}$ in this solvent. ${ }^{9}$ However, as long as $\Delta H^{*}$ is positive, even though very small, arguments for a simple mechanism can be made using non-specific steric factors or ineffective collisions as the basis for unusual rate-activation parameter relationships. Such arguments have recently been invoked in related studies. ${ }^{8,10}$

In this paper we report the results of a kinetic investigation of the dimerization of $\mathrm{DEF}^{--}$ in acetonitrile. This study resulted in the first observation of negative enthalpies of activation for electrohydrodimerization of activated olefins. The results strongly support the earlier discussion ${ }^{7}$ concerning rate-activation parameter relationship. The only previous reports of negative activation enthalpies for electrodimerization that we are aware of were from this laboratory and deal with dimerization of 9-substituted anthracene anion radicals ${ }^{11}$ and the formation of dithionate from sulfur dioxide anion radical. ${ }^{12}$

\section{RESULTS}

Kinetic Method. The kinetics of the reactions of $\mathrm{DEF}^{--}$were investigated using double potential step chronoamperometry (DPSC). ${ }^{13}$ The cyclic voltammetric peaks for the formations and oxidation of the anion radical were first centered in a $600 \mathrm{mV}$ sweep interval, the extremes of which were then used for the potential step experiments. Rate constants were then calculated from theoretical data for a second order reaction of the anion radical.

Table 1. Reaction order data for the dimerization of diethylfumarate anion radical in acetonitrile. ${ }^{a}$

\begin{tabular}{ccccc}
\hline$\left[\mathrm{H}_{2} \mathrm{O}\right]^{b} / \mathrm{mM}$ & {$[\mathrm{DEF}]^{b} / \mathrm{mM}$} & $T / \mathrm{K}$ & $R_{\mathrm{A} / \mathrm{B}}^{c}$ & $B_{\mathbf{x}}^{d}$ \\
\hline 69 & $\mathrm{v}$ & 291 & 1.9 & \\
139 & $\mathrm{v}$ & 291 & 1.9 & \\
$\mathbf{v}$ & 0.50 & 273 & & 1.2 \\
$\mathrm{v}$ & 1.0 & 273 & & 1.2 \\
$\mathrm{v}$ & 2.0 & 273 & & 1.1 \\
$\mathrm{v}$ & 4.0 & 273 & & 1.2 \\
$\mathrm{v}$ & 8.0 & 273 & & 1.3 \\
\hline
\end{tabular}

${ }^{a}$ Kinetic measurements by double potential step chronoamperometry in solvent containing $\mathrm{Bu}_{4} \mathrm{NBF}_{4}$ $(0.1 \mathrm{M}) .{ }^{b}$ Entries labelled $\mathrm{v}$ indicate that this was the variable in the set of experiments. ${ }^{c}$ The sum of the reaction orders in DEF- over [DEF] ranging from 0.50 to $4.0 \mathrm{mM}{ }^{d}{ }^{d}$ The reaction order in water over the concentration range, 69 to $555 \mathrm{mM}$. 
Table 2. Kinetic and activation parameters for the dimerization of diethylfumarate anion radical in acetonitrile. ${ }^{a}$

\begin{tabular}{ccccc}
\hline$\left[\mathrm{H}_{2} \mathrm{O}\right] / \mathrm{mM}$ & {$[\mathrm{DEF}] / \mathrm{mM}$} & $\Delta H^{*} /(\mathrm{kcal} / \mathrm{mol})$ & $\Delta S^{\mp} /(\mathrm{cal} / \mathrm{K} \mathrm{mol})$ & $10^{-3} \mathrm{k}^{b} / \mathrm{M}^{-1} \mathrm{~s}^{-1}$ \\
\hline 35 & 4.0 & -4.1 & -56 & 5.5 \\
35 & 8.0 & -3.3 & -53 & 7.8 \\
69 & 2.0 & -3.9 & -53 & 17.3 \\
69 & 4.0 & -3.0 & -50 & 16.1 \\
69 & 8.0 & -3.3 & -51 & 18.5 \\
139 & 1.0 & -3.7 & -51 & 34.7 \\
139 & 2.0 & -3.8 & -52 & 33.5 \\
139 & 4.0 & -3.0 & -48 & 38.0 \\
278 & 0.25 & -3.5 & -4.8 & 107 \\
278 & 0.50 & -4.4 & -52 & 94 \\
278 & 1.0 & -3.6 & -49 & 81 \\
278 & 2.0 & -4.0 & -51 & 165 \\
417 & 0.25 & -3.7 & -48 & 219 \\
417 & 0.50 & -4.3 & -50 & 146 \\
417 & 1.0 & -3.5 & -47 & 279 \\
555 & 0.25 & -3.9 & -48 & 266 \\
555 & 0.50 & -4.3 & -49 & 222 \\
555 & 1.0 & -3.2 & -46 & \\
& & $-3.7 \pm 0.4$ & $-50 \pm 2$ &
\end{tabular}

${ }^{a}$ In solvent containing $\mathrm{Bu}_{4} \mathrm{NBF}_{4}(0.1 \mathrm{M})$ at temperatures ranging from 273 to $293 \mathrm{~K} .{ }^{b}$ The pseudo second order rate constant at $273.2 \mathrm{~K}$.

Kinetic Results. Reaction orders in water and in anion radical were determined using as wide as possible variation of water and DEF concentrations, respectively, in the usual manner. ${ }^{14}$ The data are summarized in Table 1 . The reaction order in DEF ${ }^{-}$- was observed to be 1.9 and that in water 1.2 indicating a reasonably good fit to rate law (4), which is

$$
-\mathrm{d}\left[\mathrm{DEF}^{-}\right] / \mathrm{d} t=k_{2} K_{1}\left[\mathrm{DEF}^{-}\right]^{2}\left[\mathrm{H}_{2} \mathrm{O}\right]
$$

consistent with mechanism (1) $+(2)$. The slightly greater than unity reaction order in water could be due to a small contribution from reaction (5).

$$
2 \mathrm{~A}^{\cdot-} / \mathrm{H}_{2} \mathrm{O} \stackrel{k_{5}}{\longrightarrow} \text { Dimer }
$$

However, this does not explain the small discrepancy in the anion radical reaction order. In any event the reaction order data support mechanism $(1)+(2)$ as the predominant reaction pathway.

Two detailed sets of experiments were carried out to determine the activation parameters of the dimerization reaction. Data are reported in Table 2 for the solvent/ electrolyte, acetonitrile/Bu $/ \mathrm{NBF}_{4}(0.1 \mathrm{M})$ and in Table 3 for acetonitrile/Bu $\mathrm{NBF}_{4}(0.05 \mathrm{M})$. The water concentration was varied from 0.035 to $0.555 \mathrm{M}$ and substrate concentrations from 0.25 to $8 \mathrm{mM}$ were used. At the higher supporting electrolyte concentration $(0.1 \mathrm{M})$, $\Delta H^{*}$ was observed to be $-3.7 \pm 0.4 \mathrm{kcal} / \mathrm{mol}$ while $\Delta S^{\neq}$was $-50 \mathrm{cal} / \mathrm{K} \mathrm{mol}$. Essentially identical results were obtained at the lower electrolyte concentration (Table 3 ). In this case values of $-3.5 \pm 0.4 \mathrm{kcal} / \mathrm{mol}$ and $-50 \mathrm{cal} / \mathrm{K} \mathrm{mol}$ were observed for $\Delta H^{+}$and $\Delta S^{\neq}$, 
Table 3. Kinetic and activation parameters for the dimerization of diethylfumarate anion radical in acetonitrile. ${ }^{a}$

\begin{tabular}{ccccc}
\hline$\left[\mathrm{H}_{2} \mathrm{O}\right] / \mathrm{mM}$ & {$[\mathrm{DEF}] / \mathrm{mM}$} & $\Delta H^{+} /(\mathrm{kcal} / \mathrm{mol})$ & $\Delta S^{\mp} /(\mathrm{cal} / \mathrm{K} \mathrm{mol})$ & $10^{-3} k^{b} / \mathrm{M}^{-1} \mathrm{~S}^{-1}$ \\
\hline 69.4 & 2.0 & -3.3 & -51 & 16.2 \\
139 & 1.0 & -3.2 & -48 & 32.3 \\
139 & 2.0 & -3.1 & -48 & 46.3 \\
278 & 0.5 & -3.8 & -50 & 81.6 \\
278 & 1.0 & -4.3 & -51 & 83.6 \\
& & $-3.5 \pm 0.4$ & $-50 \pm 1.1$ &
\end{tabular}

${ }^{a}$ In solvent containing $\mathrm{Bu}_{4} \mathrm{NBF}_{4}(0.05 \mathrm{M})$, at temperatures ranging from 273 to $293 \mathrm{~K} .{ }^{b}$ The pseudo second order rate constant at $273.2 \mathrm{~K}$.

respectively. The variations in the value of $k_{273.2}$, the pseudo-second-order rate constant at constant $\left[\mathrm{H}_{2} \mathrm{O}\right]$ at different substrate concentrations suggest that the observed deviations in reaction orders mentioned earlier may well be due to error introduced by the fact that the electrode response is not ideal. It is commonly observed that processes affected by adsorption become less ideal as the amount of water in non-aqueous solvents is increased. The standard deviations in the activation parameters, considering the wide range of experimental conditions lends a considerable degree of confidence to the mean values.

Attempts to Determine Equilibrium Constants for Reaction (1). A number of attempts were made to determine the equilibrium constants for the formation of $\mathrm{DEF}{ }^{-} / \mathrm{H}_{2} \mathrm{O}$ using phase selective second harmonic a.c. voltammetry. The equilibrium constants observed depended strongly on the measurement parameters, differing with frequency and phase. The observed values also were dependent upon the substrate concentrations which suggests interference from the kinetics. It was concluded that reliable results could not be obtained and attempts were discontinued.

\section{DISCUSSION}

Practically all simple one-step chemical reactions exhibit appreciable positive activation enthalpies. For second order reactions involving neutral reactants and products, the charge contribution to $\Delta H^{+}$is expected to be minimal and in many cases orbital factors predominate. Even second order reactions between ions of opposite charge are not always diffusion controlled reflecting the fact that orbital considerations can be a factor even in these cases. The dimerization of ion radicals represents a special case. Since the reactants in these reactions are of the same charge, the charge contribution inhibits the reaction and both charge and orbital factors contribute to making $\Delta H^{+}$more positive. We are not aware of authentic simple second order reactions with activation enthalpies less than those for the corresponding diffusion controlled reactions in the particular solvent system. Thus, it would appear that comparing $\Delta H^{+}$with second order rate constants for a reaction should provide a useful criterion to use in deciding whether a reaction is of the simple one step variety or more complex. For example, if $\Delta H^{+}$for a reaction in DMF is observed to be less than about $2 \mathrm{kcal} / \mathrm{mol}$, the value for diffusion in that solvent, ${ }^{9}$ and the rate constant at ambient temperature is considerably less than about $10^{9} \mathrm{M}^{-1} \mathrm{~s}^{1}$, it is highly likely that the reaction is more complex than a simple one step reaction. This is not in any way meant to imply that activation entropies cannot be greater than those for diffusion. The argument is based upon

Acta Chem. Scand. B 39 (1985) No. 6 
the activation energy-rate constant relationship expected to prevail under most circumstances.

So far we have been unable to establish the existence of any simple one step rate determining dimerizations of anion or cation radicals. The dimerization of 9-substituted anthracene anion radicals was expected to fall in this category since the products are stable dianions and under conditions where the dissociation of the dianions can be neglected the kinetics indicate rate law (6). ${ }^{15}$ However, the activation parameters are not consistent with simple reaction (7). ${ }^{11}$ Activation enthalpies of 1.2 and $-0.2 \mathrm{kcal} / \mathrm{mol}$ were observed in DMF for anion radicals where $\mathrm{X}$ is $\mathrm{CN}$ and $\mathrm{NO}_{2}$, respectively.

$$
\begin{aligned}
& \text { Rate }=k_{\text {app }}\left[\mathrm{AN}-\mathrm{X}^{\cdot-}\right]^{2} \\
& 2 \mathrm{AN}-\mathrm{X}^{\cdot-} \stackrel{K_{7}}{\rightleftarrows} \cdot-\mathrm{X}-\mathrm{AN}-\mathrm{AN}-\mathrm{X}^{\cdot-}
\end{aligned}
$$

The corresponding values of $k_{\text {app }}$ at $20^{\circ} \mathrm{C}$ were of the order of $2 \times 10^{5}$ and $2 \times 10^{6} \mathrm{M}^{-1} \mathrm{~s}^{-1}$, respectively. A more recent study on the dimerization of $\mathrm{AN}-\mathrm{CN}^{-}$in various solvents has substantiated the earlier studies and in one case a negative $\Delta H^{\ddagger}$ was found for this reaction as well. ${ }^{16}$ Thus, the mechanism of this reaction must accomodate this. A mechanism consistent with the data involves the initial association into a complex (8) followed by rate determining bond formation (9). ${ }^{11,15}$

$$
\begin{aligned}
& 2 \mathrm{AN}-\mathrm{X}^{\cdot-} \stackrel{K_{8}}{\rightleftarrows} \mathrm{AN}-\mathrm{X}^{\cdot-} / \mathrm{AN}-\mathrm{X}^{\cdot-} \\
& \mathrm{AN}-\mathrm{X}^{\cdot-} / \mathrm{AN}-\mathrm{X}^{\cdot-} \stackrel{k_{9}}{\rightleftarrows} \cdot \mathrm{X}-\mathrm{AN}-\mathrm{AN}-\mathrm{X}^{\cdot-}
\end{aligned}
$$

The pre-equilibrium association of $\mathrm{DEF}^{--}$with water (1) followed by rate determining coupling reaction (2) is a somewhat more clearly defined mechanism. ${ }^{1,7}$ While there is no information on the nature of the dimeric dianion complex in reaction (8), equilibrium (1) is quite well defined. It is known that water is strongly hydrogen bonded to DMF and other aprotic solvents and a number of examples of hydrogen bonding equilibria (1) have been investigated. ${ }^{17-19}$ The pertinent activation and thermodynamic parameters have been evaluated in DMF. The apparent activation enthalpy was observed to be comprised of a negative $\Delta H_{1}^{\circ}(-5.9 \mathrm{kcal} / \mathrm{mol})$ and a positive $\Delta H_{2}^{*}(7.2 \mathrm{kcal} / \mathrm{mol})$ with an overall value less than expected for a diffusion controlled reaction while the rate constant at ambient temperature was about 7 orders of magnitude less than expected if the reaction were controlled by diffusion of the reactants.

The dimerization of $\mathrm{DEF}^{--}$in acetonitrile (Tables 1-3) fits the general criteria expected for mechanism (1)+(2). In this case we have been unable to study equilibrium (1) and thus our apparent activation enthalpies cannot be broken down into the constituent thermodynamic and activation contributions. However, the fact that $\Delta H_{\text {app }}^{+}$is strongly negative in this case $(-3.7 \mathrm{kcal} / \mathrm{mol})$ there is little doubt about the complex nature of the reaction. The reaction order data are in reasonable accord with pre-equilibrium mechanism $(1)+(2)$. Aside from the small inconsistencies noted earlier, it appears safe to conclude that there is no mechanism change in going from DMF to acetonitrile as solvént. The negative $\Delta H_{\text {app }}^{\neq}$ suggests a more dominating role of $\Delta H_{1}^{\mathrm{o}}$ in this case.

The observations of low and negative activation enthalpies have recently become a rather common phenomenon. The explanation for the energetics of these reactions is that

Acta Chem. Scand. B 39 (1985) No. 6 
the reactions proceed through at least one intermediate, present in low concentration and usually refered to as a complex. This general reaction scheme is illustrated by eqns. $(10)+(11)$ and gives rise to rate law (12). Because the heat of formation of the complex, $\Delta H_{10}^{\mathrm{o}}$, can be negative, the overall activation enthalpy, $\Delta H_{\mathrm{app}}^{+}$, which is made up of two terms (13) may assume appreciable negative values.

$$
\begin{aligned}
& \mathrm{A}+\mathrm{B}(\text { or } \mathrm{A}) \underset{k_{-10}}{\stackrel{k_{10}}{\longrightarrow}} \text { Complex } \\
& \text { Complex } \stackrel{k_{11}}{\longrightarrow} \text { Products } \\
& \text { Rate }=\left(k_{10} k_{11} /\left(k_{-10}+k_{11}\right)\right)[\mathrm{A}][\mathrm{B}] \\
& \Delta H_{\mathrm{app}}^{+}=\Delta H_{10}^{\mathrm{o}}+\Delta H_{11}^{\neq} \\
& \Delta S_{\mathrm{app}}^{+}=\Delta S_{10}^{\mathrm{o}}+\Delta S_{11}^{\neq}
\end{aligned}
$$

Since the corresponding entropy terms are both expected to be negative, $\Delta S_{\text {app }}^{\neq}$(14) usually has appreciable negative values which results in $\Delta G_{\text {app }}^{\neq}$with positive values and the reactions sometimes are relatively slow.

General reaction scheme $(10)+(11)$ has been implicated in a number of cases. The activation enthalpies are found to be significantly smaller than those expected for reactions controlled by translational diffusion. Well characterized examples include the dimerization of phenoxy radicals ${ }^{20-23}$ as well as nitroxide radicals, ${ }^{24}$ the proton transfer between 2,4-dinitrophenyl and aliphatic tertiary amines, ${ }^{25}$ several photochemical reactions, ${ }^{26-28}$ an example of the Diels-Alder reaction ${ }^{29}$ and the reaction of methyl phenyl ketene. ${ }^{30}$ Thus, there is ample precedent for this type of behaviour aside from the chemistry of ion radicals. Since ion radical chemistry abounds with examples of coupled equilibria ${ }^{31,32}$ it is very likely that many more examples of negative activation enthalpies will be found upon examinations of the temperature dependence of the reaction kinetics.

\section{EXPERIMENTAL}

The cells, electrodes, instruments and data handling procedures were the same as used in other papers in this series. ${ }^{1-7}$ Reagent grade MeCN containing the supporting electrolyte $\left(\mathrm{Bu}_{4} \mathrm{NBF}_{4}\right)$ was passed through a column containing neutral alumina before use.

Acknowledgement. The department of chemistry, University of Utah, is gratefully acknowledged for facilities for V.D.P. during his sabbatical leave.

\section{REFERENCES}

1. Parker, V.D. Acta Chem. Scand. B 35 (1981) 147.

2. Parker, V.D. Acta Chem. Scand. B 35 (1981) 149.

3. Parker, V.D. Acta Chem. Scand. B 35 (1981) 279.

4. Parker, V.D. Acta Chem. Scand. B 35 (1981) 295.

5. Margaretha, P. and Parker, V.D. Acta Chem. Scand. B 36 (1982) 269.

6. Lerflaten, O. and Parker, V.D. Acta Chem. Scand. B 36 (1982) 225.

7. Parker, V.D. Acta Chem. Scand. B 37 (1983) 393. 
8. Amatore, C., Pinson, J. and Savéant, J.M. J. Electroanal. Chem. 137 (1982) 143.

9. Aalstad, B. and Parker, V.D. Acta Chem. Scand. B 36 (1982) 295.

10. Savéant, J.M. Acta Chem. Scand. B 37 (1983) 365.

11. Hammerich, O. and Parker, V.D. Acta Chem. Scand. B 37 (1983) 379.

12. Parker, V.D. Acta Chem. Scand. A 37 (1983) 423.

13. Schwarz, W.M. and Shain, I. J. Phys. Chem. 69 (1965) 30.

14. Parker, V.D. Acta Chem. Scand. B 35 (1981) 233.

15. Hammerich, O. and Parker, V.D. Acta Chem. Scand. B 35 (1981) 341.

16. Eliason, R., Hammerich, O. and Parker, V.D. Manuscript in preparation.

17. Parker, V.D. Acta Chem. Scand. B 38 (1984) 125.

18. Parker, V.D. Acta Chem. Scand. B 38 (1984) 189.

19. Eliason, R. and Parker, V.D. Acta Chem. Scand. B 38 (1984) 741.

20. Khudyakov, I.V., Levin, P.P. and Kuzmin, V.A. Usp. Khim. 49 (1980) 1990.

21. Levin, P.P., Khudyakov, I.V. and Kuzmin, V.A. Int. J. Chem. Kinet. 12 (1980) 147.

22. Williams, D.J. and Kreilick, R. J. Am. Chem. Soc. 90 (1968) 2775.

23. Mahoney, L.R. and DaRooge, M.A. J. Am. Chem. Soc. 97 (1975) 4722.

24. Bowman, D.F., Gillan, T. and Ingold, K.U. J. Am. Chem. 93 (1971) 6555.

25. Caldin, E.F. and Tortschanoff, K.J. J. Chem. Soc. Faraday Trans. 1, 74 (1978) 1804.

26. Turro, N.J., Lehr, G.F., Butcher, J.A., Jr., Moss, R.A. and Guo, W. J. Am. Chem. Soc. 104 (1982) 1754.

27. Wong, P.C., Criller, D. and Scaiano, J.C. Chem. Phys. Lett. 83 (1981) 69.

28. Maharaj, U. and Winnik, M.A. J. Am. Chem. Soc. 103 (1981) 2328.

29. Kiselev, V.D. and Miller, J.C. J. Am. Chem. Soc. 97 (1975) 4036.

30. Jähme, J. and Rüchardt, C. Tetrahedron Lett. 23 (1982) 4011.

31. Parker, V.D. Adv. Phys. Org. Chem. 19 (1983) 131.

32. Hammerich, O. and Parker, V.D. Adv. Phys. Org. Chem. 20 (1984) 55.

Received September 6, 1984. 